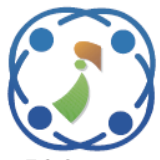

\title{
Smart Variable Rotor of Vertical Axis Wind Turbine with Faster Cut-in Speed and Wide Range Extract Power Using Artificial Intelligent
}

\author{
Jazuli Fadil ${ }^{1,2}$ \\ Soedibyo Soedibyo ${ }^{1}$ \\ Mochamad Ashari ${ }^{1 *}$ \\ ${ }^{I}$ Department of Electrical Engineering, Institut Teknologi Sepuluh Nopember, Surabaya, Indonesia \\ ${ }^{2}$ Department of Electrical Engineering, Politeknik Negeri Banjarmasin, Banjarmasin, Indonesia \\ * Corresponding author's Email: ashari@ee.its.ac.id
}

\begin{abstract}
This paper presents the standalone type vertical axis wind turbine (VAWT) smart rotor using variable diameter rotor (VDR) in order to tap constant power and maintain cut-in wind speed. VDR is a smart variable rotor capable of operating at a low wind speed, in which the width of diameter rotor is adjustable using actuators. The VDR rotor is connected to the permanent magnet synchronous generator (PMSG) and a DC-DC boost converter. The controller of VDR rotors uses fuzzy logic controller (FLC). The FLC variable inputs are wind speed data and power output, broken down into cluster groups to determine the diameter rotor position. The wind speed data as fuzzy input are produced by wind speed estimator using artificial neural network (ANN) to maintain cut-in speed to be faster. The velocity movement of VDR is limited from $75 \mathrm{~cm}$ to $150 \mathrm{~cm}$. The VDR extension increases by $25 \%$ when the wind speed decreases from 8 to $6 \mathrm{~m} / \mathrm{s}$ to obtain consistent power at 150 Watt. The experimental of VDR system is tested at low wind speeds ranging from 1 to $8 \mathrm{~m} / \mathrm{s}$ as a verification of the control system. The result showed that the VDR produced five times increase in efficiency with faster cut-in wind speed at $2.0 \mathrm{~m} / \mathrm{s}$.
\end{abstract}

Keywords: Smart rotor, Variable speed, Variable diameter, Swept area, Dynamic rotor.

\section{Introduction}

Rapid occurrence of global warming and decreasing energy reserves has become a global issue and a challenge for researchers. One of many means of preservation is to develop renewable energy sources that are environmentally friendly, such as solar cell clustering, wind farm optimization, and wind turbine control optimization by incorporating modern technology to improve the efficiency of renewable energy [1-5].

Generally, wind turbines are divided into two types based on the rotation, namely horizontal axis wind turbines (HAWTs) and vertical axis wind turbines (VAWTs). HAWTs are usually used on a large scale wind turbine power, but these turbines are highly wind dependent, require a complex yaw mechanism, are very expensive $[6,7]$. On the other hand, VAWTs have much better performance and are suitable in rural and remote areas because they are able to operate in all wind directions, and the generator can be placed close to the ground which, in turn, results in easier maintenance and lower cost $[8$, 9].

The power output of wind turbine depends on wind speed, power coefficient, and swept area. The swept area as rotor of VAWTs consists of blades and rotor diameter. The rotor blades with variable pitch control are usually used for aerodynamic optimization on the side of the rotor using ANN, fuzzy, PID and other artificial intelligence controls to limit the power output during strong wind conditions or above the wind speed rating [10-14].

Smart rotor design for aerodynamic optimization with the variable swept area (VSA) concept or telescopic blade is designed to achieve constant power [15-19]. The controls used are fuzzy, PID by applying adjustable swept area that the turbine is capable of operating at low wind speeds or being activated at either below wind speed rating or above wind speed rating. When below the wind speed rating, 


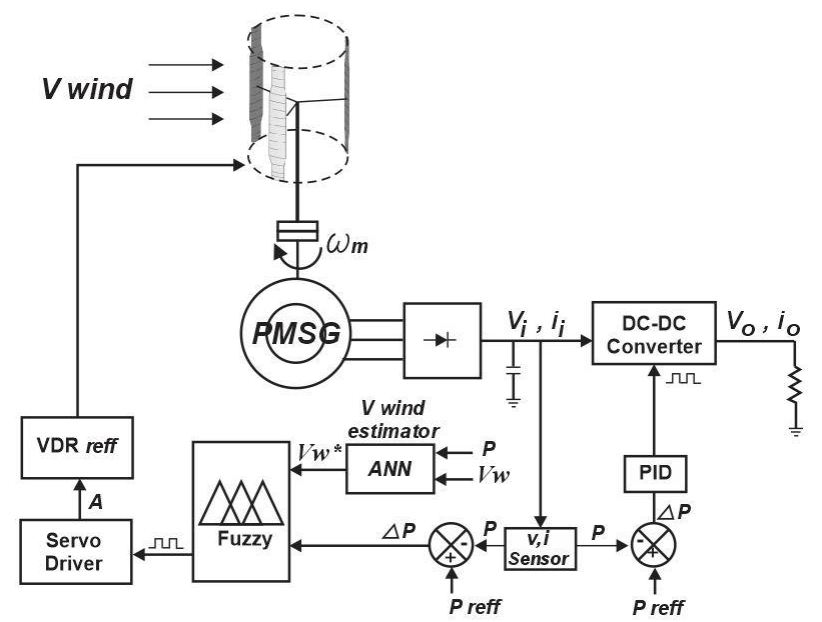

Figure. 1 VAWT control system with VDR

the VSA size will be maximum; when above the wind speed rating, the VSA will track the constant power by changing the VSA size close to the minimum position. Size and dynamic rotor with blade transitioning capability variables aims to increase the power coefficient of VAWT [20].

However, the aforementioned controls cannot maintain cut-in speed when the wind speed is at below rating. In a case when the wind speed is below its rating speed, the variable pitch control will remain at optimum fixed pitch angle [21-23], pitch angle change occurs only when the turbine operation passes the wind speed rating to limit the power output. Meanwhile, variable swept area at low wind speed will remind at maximum position.

The contribution of this paper is to accelerate cutin speed and maintain the constant power of VAWTs using VDR as smart rotor as shown in Fig. 1. VDR has an adjustable rotor diameter capable of extending and retracting based on wind speed using FLC and ANN on rotor side, and PID controller on converter side. The VDR rotor is connected to permanent magnet synchronous generator (PMSG) and a DCDC boost converter with PID controller. FLC is applied on the actuator interface of VDR, with FLC input being data on wind speeds and generator power output. Wind speed data are produced by wind speed estimator using ANN. By determining the wind speed earlier, the system can work better to accelerate the cut-in speed, so that short term wind speed forecasting is needed using an ANN placed as FLC input. The performance of the proposed method is evaluated both by simulation and laboratory experiments.

This paper is organized as follows. Section 2 presents the VAWT modeling concept. Section 3 discusses the proposed VDR system. Section 4 explains the experimental set-up. The assessment of the proposed method is presented in Section 5. Finally, section 6 concluded this paper.

\section{Proposed VDR system}

\subsection{Operating cut-in speed region}

The relationship between wind speed and generator power is divided into three categories as shown in Fig. 2. Cut-in wind speed is the lowest wind speed to start producing power, rated wind speed is the minimum wind speed to procure rated power, and the maximum speed over rated power is denoted as cut-out wind speed. In region 1, the wind speed is lower than cut-in, in which general of wind turbine fails to produce power output due to low wind speed being below the cut-in wind speed. The region 2 position is between cut-in and rated wind speed, in which the wind captured is transformed into valuable power. Region 3 is in between rated wind speed and cut-out wind speed as full load region where a constant power is realized $[24,25]$.

In VDR, the controller is designed into three operating regions. The first one is below cut-in region; the turbine works at lower $C p$ to increase the power at lower wind speed, the position of the rotor diameter is adjusted into optimum diameter with cutin wind speed between $1.5-2.5 \mathrm{~m} / \mathrm{s}$ by changing the diameter size. Changes in rotor diameter can be seen in the VDR concept features in Fig. 3 and Fig. 4.

The optimum reference diameter at the lowest wind speed will be the membership function of FLC output to tap cut-in wind speed in which the lowest wind speed data must be identified earlier using shorterm forecasting with ANN. When passing the rated power region limit, the control strategy is to maintain the rated power constant by reducing the diameter size and minimizing aerodynamic loads of the wind turbine.

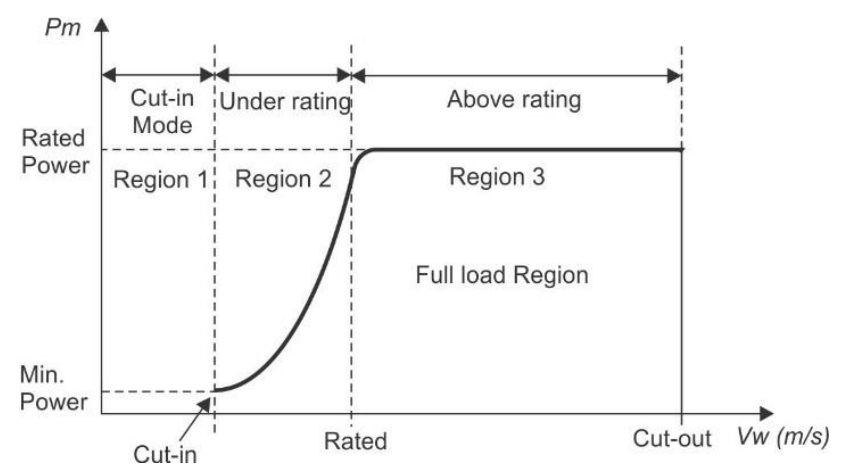

Figure. 2 VAWT control system with VDR 


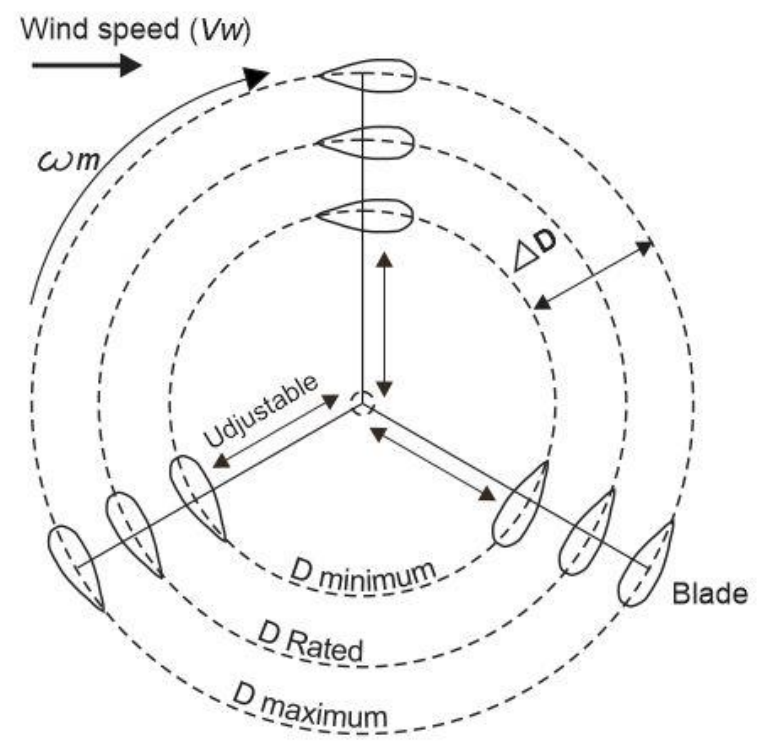

Figure. 3 The VDR rotor concept

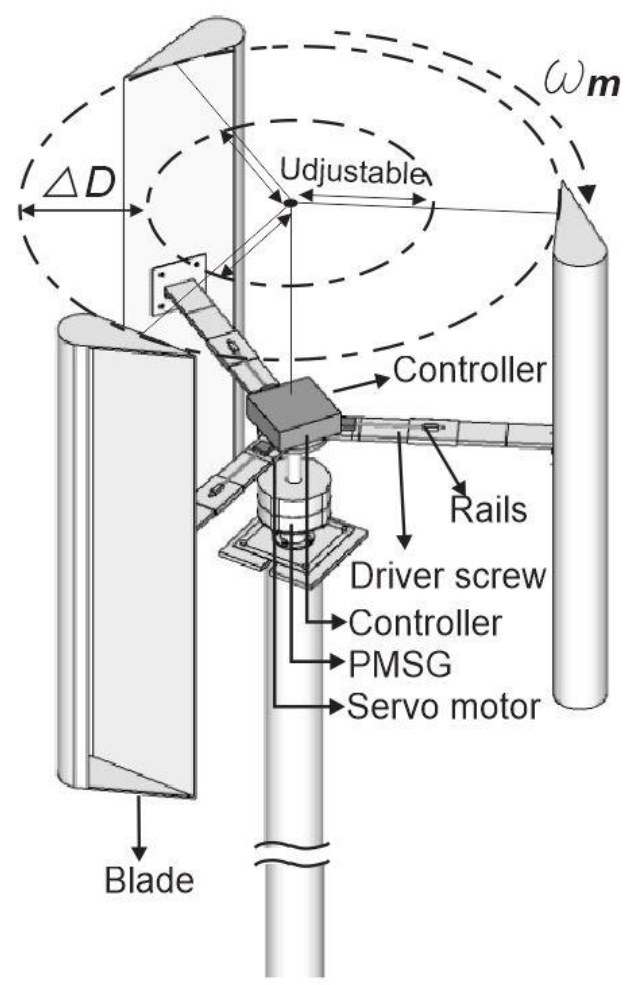

Figure. 4 The VDR feature

\subsection{VAWT model}

The concept of wind energy converting mechanical power into electrical energy is presented in Fig. 5, in which parameter $D$ is the rotor diameter set to be adjustable. The wind power captured by the rotor turbine/blades is converted into mechanical power calculated as follows:

$$
P_{m}=\frac{1}{2} \rho \cdot A \cdot v^{3} \cdot C p(\theta, \lambda)
$$

In which $C p(\Theta, \lambda)$ is a power coefficient of the blade as a nonlinear function of tip speed ratio $(\lambda)$ and pitch angle $(\Theta)$. The maximum $C p$ value of the current advanced technology according to the Betz limit theory is 0.59 [26]. $A$ is swept area $\left(\mathrm{m}^{2}\right)$ which captures $v$ as cubic function of wind speed $(\mathrm{m} / \mathrm{s})$, and $\rho$ is air density of $1.225 \mathrm{~kg} / \mathrm{m}^{3}$.

Swept area $A$ consists of turbine height $h$ and rotor diameter $D$, in which diameter $D$ in design variables, ranging from $75 \mathrm{~cm}$ to $100 \mathrm{~cm}$, which means that diameter variable is a diameter capable to extend and retract to face dynamic wind speed as shown Fig. 3. This diameter change is controlled by FLC on the radius side of the turbine which has three blades as VDR, in which each change in the variable diameter causes the swept area to change, so the power output also changes. It is affected by the tip speed ratio (TSR) and $C p$ during the transition change of the diameter. TSR is defined as the ratio of the blade tip speed to the incoming wind speed, in which wind turbine can achieve wider range extract power by maintaining optimal TSR at different wind speed. The TSR $\lambda$ is formulated as follows [27].

$$
\lambda=\frac{\omega_{\mathrm{m}} r_{t}}{\mathrm{v}_{\mathrm{w}}}
$$

Where $\lambda$ is the TSR, $\omega_{m}$ is the angular speed of turbine $(\mathrm{rad} / \mathrm{s}), r_{t}$ is the radius of turbine and $v_{w}$ is the wind speed $(\mathrm{m} / \mathrm{s})$. The mechanical angular speed of the rotor and torque can be formulated as:

$$
\mathrm{J} \frac{\mathrm{d} \omega_{\mathrm{m}}}{\mathrm{dt}}=T_{e}-T_{m}-B \cdot \omega_{m}
$$
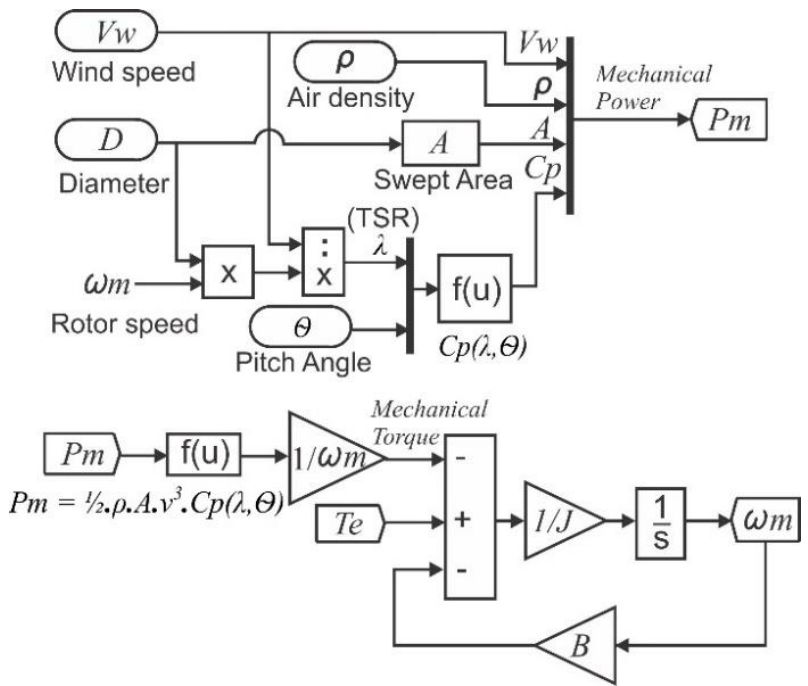

Figure. 5 Wind turbine model 
Where $J$ is the combined inertia of rotor and the wind turbine $\left(\mathrm{kg} . \mathrm{m}^{2}\right), T_{e}$ is the electromagnetic torque $(N . m)$, and $B$ is the viscous friction of the rotor (N.m.s/rad). Based on Eq. (1) and Eq. (2), the mechanical torque of wind turbine can be formulated as:

$$
T_{m}=\frac{P_{m}}{\omega_{m}}=\frac{\frac{1}{2} \rho \cdot A \cdot v^{3} \cdot C p(\theta, \lambda)}{\omega_{m}}
$$

Where $T_{m}$ is the mechanical torque of the turbine (N.m). To optimize the mechanical efficiency at different wind speeds, there is only one appropriate rotor speed with maximum $C p$ value and optimum tip speed ratio $[28,29]$.

\subsection{The VDR as smart rotor}

The VDR has a variable diameter rotor which can be retracted and extended based on wind speed conditions predicted by ANN as wind speed estimator. Changes on VDR size are controlled using FLC; the fuzzy inputs are wind speed and power turbine and the fuzzy output is diameter reference. VDR will affect the power output at the turbine as shown by Eqs. (5) and (6), in which $A$ is the swept area, $h$ is the height of blade, and $D$ is the diameter rotor.

$$
A=h . D
$$

Then the VDR can be calculated as follows:

$$
A=h \cdot(D+\Delta D)
$$

Where $\Delta D$ is the difference between maximum and minimum position of diameter configuration as shown in Fig. 4. Fully extended is the maximum rotor diameter when moving outward, while fully retracted is the minimum retraction of the rotor diameter when being retracted. The calculation of power produced by VDR is shown below:

Table 1. VAWT parameter

\begin{tabular}{|l|l|}
\hline Parameter & \multicolumn{1}{|c|}{ Value } \\
\hline Rated mechanical power & 500 Watt \\
\hline Number of Blade & 3 \\
\hline Diameter max & $100 \mathrm{~cm}$ \\
\hline Diameter min & $75 \mathrm{~cm}$ \\
\hline Blade height & $100 \mathrm{~cm}$ \\
\hline Blade type & Lenz \\
\hline
\end{tabular}

Table 2. Fuzzy input

\begin{tabular}{|l|l|l|l|}
\hline & $\begin{array}{c}\text { Wind Speed } \\
(\mathrm{m} / \mathrm{s})\end{array}$ & Power $(\mathrm{W})$ & Fuzzy State \\
\hline Cluster 1 & {$[1-4.68]$} & {$[0-312.5]$} & $\begin{array}{l}\text { Cut-in } \\
\text { speed }\end{array}$ \\
\hline Cluster 2 & {$[1.87-7.5]$} & {$[125-500]$} & Low speed \\
\hline Cluster 3 & {$[4.68-10.31]$} & {$[312.5-687.5]$} & $\begin{array}{l}\text { Rating } \\
\text { speed }\end{array}$ \\
\hline Cluster 4 & {$[7.5-13.12]$} & {$[500-875]$} & Strong \\
\hline Cluster 5 & {$[10.31-15]$} & {$[687.5-1000]$} & Very Strong \\
\hline
\end{tabular}

$P m=\frac{1}{2} \cdot \rho \cdot(h \cdot(D+\Delta D)) \cdot v^{3} \cdot C p(\theta, \lambda)$

The operating region of generator is when the wind speed reaches its rating. VDR will be adjusted to obtain the appropriate generator power output. VDR will be retracted when wind speed increases above the generator rating power. The mechanism of VDR system when extending or retracting based on particular wind speed becomes the fuzzy logic rule base.

The movement of VDR is adjusted by wind speed clustering as membership function input of Fuzzy Logic Controller. The linguistic variables are used to substitute the mathematical model of the dynamic system [30,31].

The VDR block diagram with FLC and ANN can be seen in Fig. 6. In the experiment, there are two ANN input signals, namely $\mathrm{P}$ and $\mathrm{Vw}, \mathrm{P}$ is the analog power output signal from the current and voltage sensors. It is then converted into 8 bit digital data via the ADC input on the microcontroller. Vw is a wind speed sensor, or anemometer in the form of an 8-bit digital signal ranging from $1 \mathrm{~m} / \mathrm{s}-12 \mathrm{~m} / \mathrm{s}$. Both $\mathrm{P}$ and Vw states are obtained from ANN offline training which is performed in a microcontroller. It yields $\mathrm{VW}^{*}$ state as wind speed forecast. This state is a digital signal from wind speed forecasting that becomes as an input for Fuzzy. Meanwhile, there are signals $\mathrm{P}$ and $\mathrm{P}$ ref, signal $\mathrm{P}$ is an analog signal from the power output $\mathrm{P}$ converted into a digital signal through the ADC. P ref is the digital reference value to obtain the error value of $\mathrm{P}$ and $\delta \mathrm{eP}$ using the following equation.

$$
\begin{gathered}
e P(k)=P(k)-P_{r e f}(k) \\
\delta e P=e P(k)-e P(k-1)
\end{gathered}
$$

The power output $\delta \mathrm{eP}$ is obtained from recent value $\mathrm{eP}$ minus with the previous error, with $\mathrm{Z}^{-1}$ being the sampling time delay. The output Fuzzy is a digital 
signal to drive the servo motor and produced VDR reference.

The process of fuzzification is assigned to the linguistic variables. The wind speed cluster as verbal value is divided into five fuzzy subsets, namely cutin speed (CS), low speed (LS), rating speed (RS), strong (S) and very strong (VS) as shown in Fig. 7. The membership function used is the triangle function.

The fuzzification process uses the center gravity method to transform the fuzzy output into the crisp output $[31,32]$. The adjustment of the rotor diameter position and variable wind speed from the sensor is processed with 25 number "if-then" rules, in which the blurring rule base is processed by inferencing system using the Mamdani method. The rules of the VDR reference is determined by considering fuzzy rules as follows:

Rules $_{i}$ : If $V_{w}$ is $X_{i}$ and $e P$ is $Y_{i}$ and $\delta e P$ is $Z_{i}$, Then $V D R_{\text {ref }}$ is $F_{i} ; i=1, \ldots, m$.

Where $X_{i}, Y_{i}, Z_{i}$ are the fuzzy set and $F_{i}$ is fuzzy singleton.

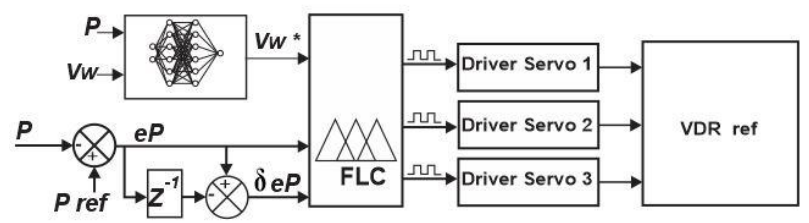

Figure. 6 The VDR control block diagram

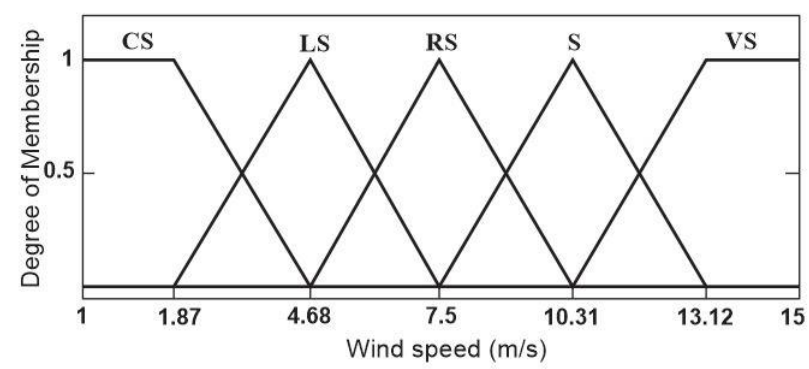

Figure. 7 Membership function of wind speed

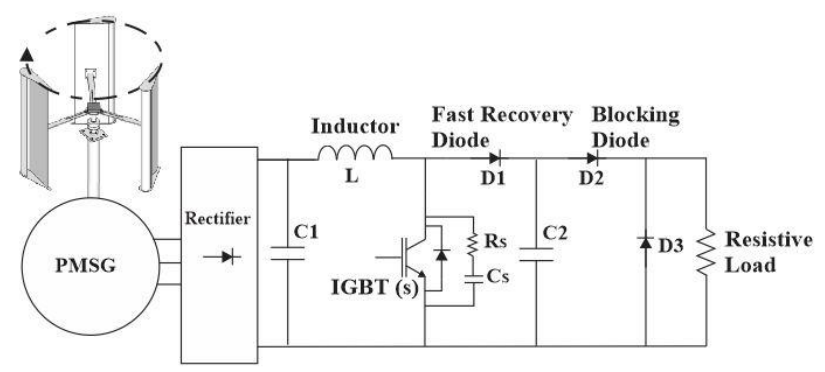

Figure. 8 Boost converter block diagram
Table 3. Parameter of boost converter

\begin{tabular}{|l|c|}
\hline \multicolumn{1}{|c|}{ Parameter } & Value \\
\hline Input Voltage & 35 Volt \\
\hline Output Voltage & 70 Volt \\
\hline Boost Inductor & $92 \mu \mathrm{H}$ \\
\hline Filter Capacitor & $378 \mu \mathrm{F}$ \\
\hline Resistive Load & $25 \mathrm{ohm}$ \\
\hline $\mathrm{Kp}$ & 0.001 \\
\hline $\mathrm{Ki}$ & 0.01 \\
\hline
\end{tabular}

Fig. 8 shows that VAWT is connected to the power converter on its PMSG to tap constant voltage. The power converter consists of an unregulated diode rectifier, which transforms AC to DC voltage [33].

The output of boost converter is connected to the resistive load in which the duty cycle configuration is controlled by the PID controller to generate pulses on IGBT(s). The ratio of duty cycle can be calculated as follows [34]:

$$
D_{c l}=\frac{T_{o n}}{T_{s}} 100 \%
$$

The voltage output of boost converter is greater than the DC voltage input because the voltage output is the sum of voltage input and inductor voltage [3537]. The inductor voltage in period $(T s)$ is zero and depends on the duty cycle that can be formulated as:

$$
D_{c l} \cdot V_{d c}+\left(1-D_{c l}\right)\left(V_{d c}-V_{\text {out }}\right)=0
$$

The input and output voltage can be formulated as:

$$
V_{\text {out }}=\frac{V_{\text {in }}}{1-D_{\text {cl }}}
$$

Where $D_{c l}$ is duty cycle of the converter, defined by $D_{c l}=T_{o n} / T_{s} ; T_{s}$ is the switching period; $T_{o n}$ and $T_{o f f}$ are the turn-on and turn-off times of the switch $S$, respectively. Eq. (12) indicates that the $V_{\text {out }}$ of the converter is always higher than its input voltage. Where Eqs. (11) and (12) are for the continous conduction mode (CCM) of the boost converter, assuming the inductor $L$ is pure inductor. CCM mode is used because to get a low output voltage ripple on the stand-alone load.

Power input equals to the power output by neglecting the losses of power converter. 


$$
P_{\text {in }}=\frac{V_{d c}^{2}}{R_{\text {in }}} \cong P_{\text {out }}=\frac{V_{d c}^{2}}{\left(1-D_{c l}\right)^{2} R_{L}}
$$

To tap constant power, PID controller is applied to the DC-DC boost converter of which equation is as follows:

$$
\begin{gathered}
u(t)=k_{s} e(t)+K_{i} \int_{0}^{t} e(t)+K_{d} \frac{d e(t)}{d t} \\
C(s)=k_{p}+\frac{K_{i}}{S}+K_{d} S
\end{gathered}
$$

Where $(\mathrm{Ki})$ and $(\mathrm{Kd})$ are integration gain and derivative gain of each constant.

\section{Wind speed estimator with ANN}

ANN is particularly used to implement nonlinear time varying input-output mapping that develops intelligent information processing system, is highly parallel and good fault-tolerance [38]. ANN is trained using data sampling on the behavior of a system. The ANN in this study used multilayer perceptron (MLP) for wind speed forecasting with off-line training. The purpose of VDR using an ANN is to establish the intelligent control of rotor diameter based on the information extraction of the wind power characteristics.

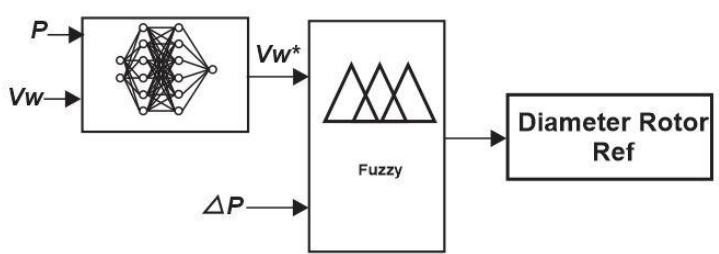

Figure. 9 ANN and Fuzzy control module of diameter rotor

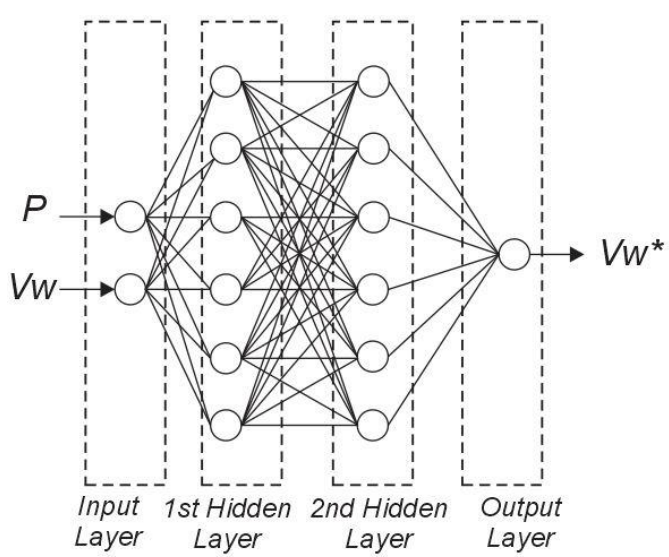

Figure. 10 Wind speed prediction ANN-based

This method requires exact past wind speed data using wind speed sensor in which the wind speed prediction result or the ANN output becomes Fuzzy input to determine the correct diameter reference as shown Fig. 9. The proposed forecasting model based on ANN has two inputs and one output for short time prediction of wind speed as shown in Fig. 10. The inputs are generator output $(P)$ and wind speed $(V w)$ data samples, recombined as "n" data pairs $\left(P_{(\mathrm{i})}, V w_{(\mathrm{i})}\right.$ I $\mathrm{i}=1 \sim \mathrm{n})$ which become the matrix input vector of ANN.

The wind speed data samples are used as target to train the layer networks, consisting of five tan sigmoid neurons in hidden layer and one linear output layer. The forecasting performance were tested using wind speed data which had never been presented to the ANN.

The wind speed forecasting with off-line training generated an average wind speed range of $1 \mathrm{~m} / \mathrm{s}-8$ $\mathrm{m} / \mathrm{s}$, the sampling period is 1 second with 500 sample data pairs. The test result is shown in Fig. 11 with an average error of 0.15 in which ANN can better track the test samples and be used to predict velocity.

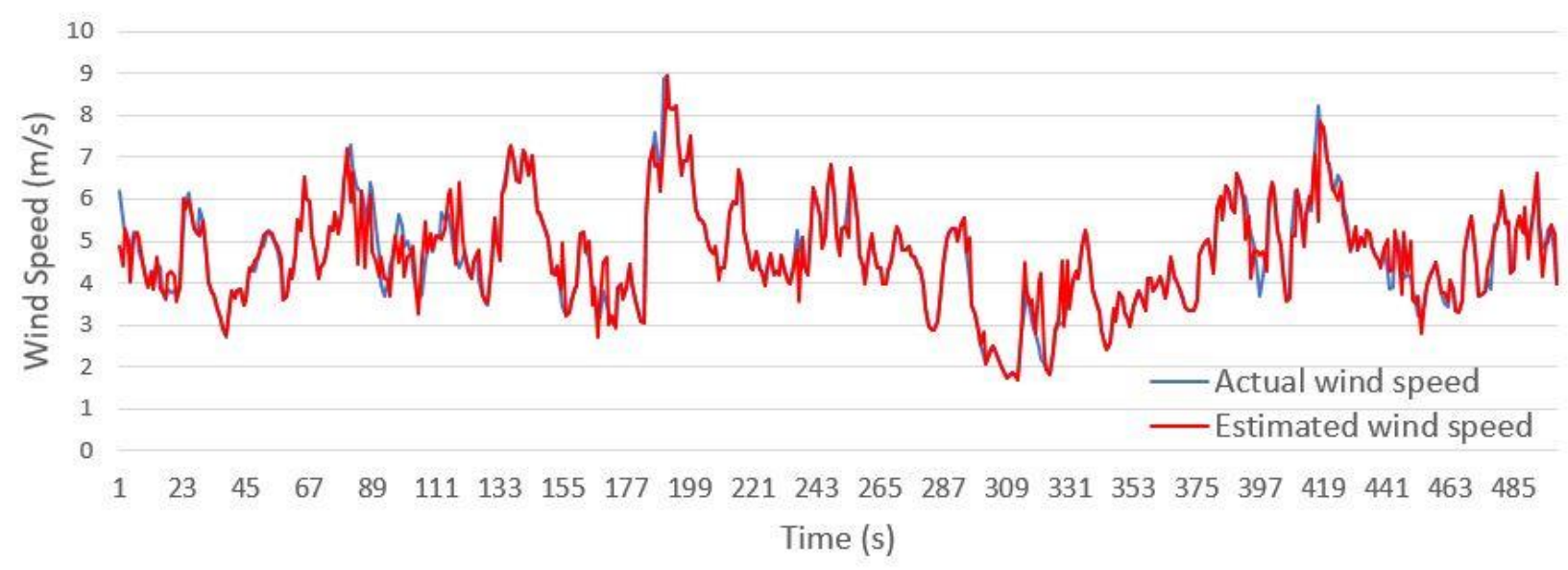

Figure. 11 Wind speed prediction 


\section{Experimental of prototype}

The VDR system configuration consists of a fan, VDR rotor, PMSG, converter, and resistive load as shown in Fig. 12. The input variable wind speed used a fan of which wind speed ranged from $1 \mathrm{~m} / \mathrm{s}$ to 20 $\mathrm{m} / \mathrm{s}$.

Fig. 13 shows the rotor diameter performance obtained for variable wind speed and different rotation (Rpm). On each diameter configuration, different power output characteristics are identified, in which these characteristics will be defined to select an operating point for the controller to work on. The optimum configuration of VDR to maintain cut-in speed is adjusted by wind speed clustering as Fuzzy membership function.

The diameter actuator obtains signal data from power controller to take appropriate power and track the turbine diameter. The actuator controller uses microcontroller to apply Fuzzy and stimulate the servo motors to adjust the diameter actuator movement. The adjustment of diameter based on wind speed forecasting uses ANN as FLC input. The FLC output is in the form of VDR reference to tap constant power.

VDR Rotor consists of variable diameter as seen in Fig. 14, in which variable diameter can extend its length at low wind speeds and retract at high wind speeds. The extension and retraction mechanism of variable diameter uses servo motor as shown Fig. 15. The VDR rotor hub is mounted to the shaft PMSG rotor as, with the PMSG output is connected to the three-phase rectifier, capacitor, converter and resistive load as shown in Fig. 8. The communication data of rotor controller and power controller uses wireless data interface as shown Fig. 16.

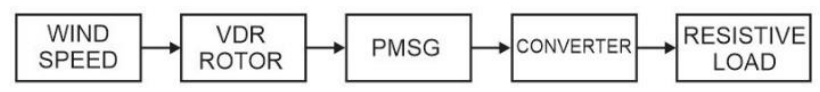

Figure. 12 The arrangement of main equipment

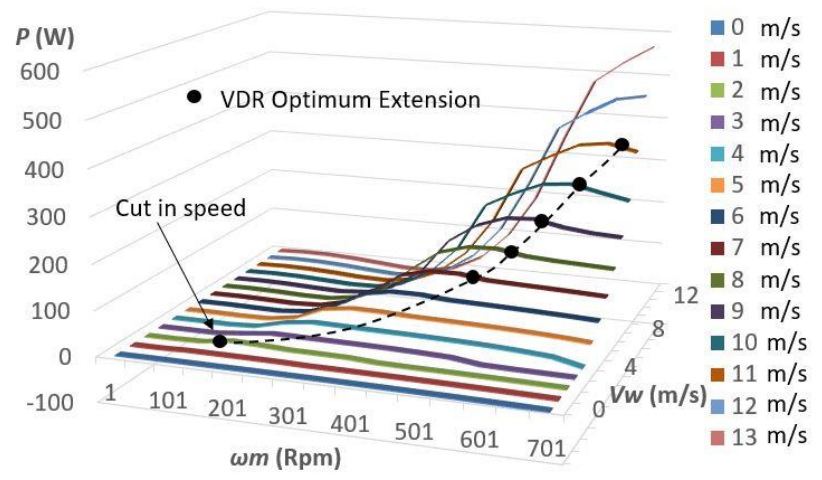

Figure. 13 Power curve of VDR extension

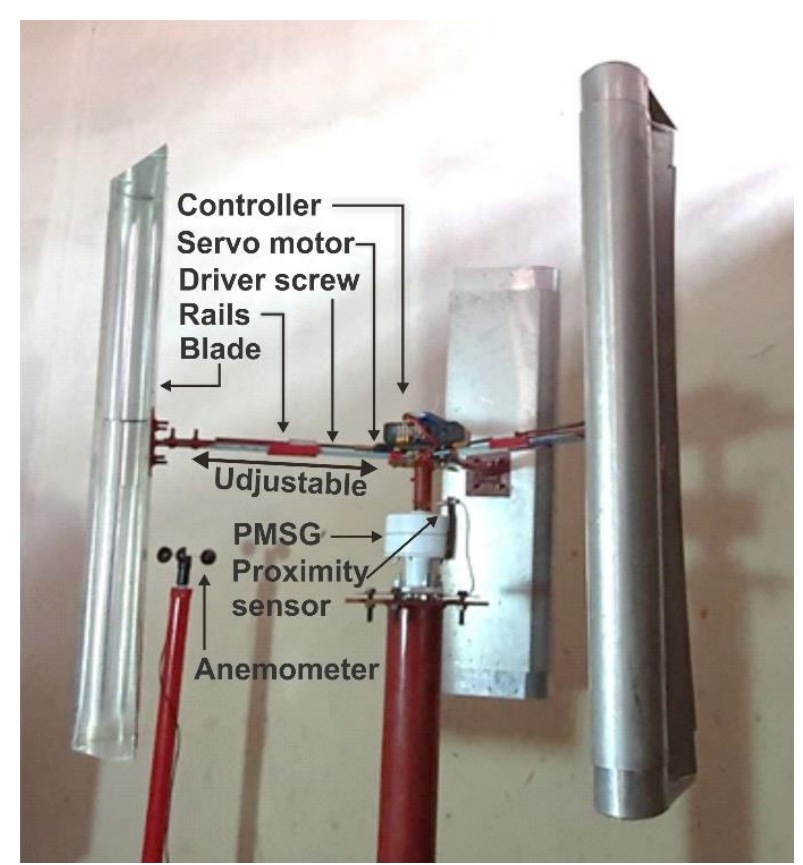

Figure. 14 The VDR actual photograph

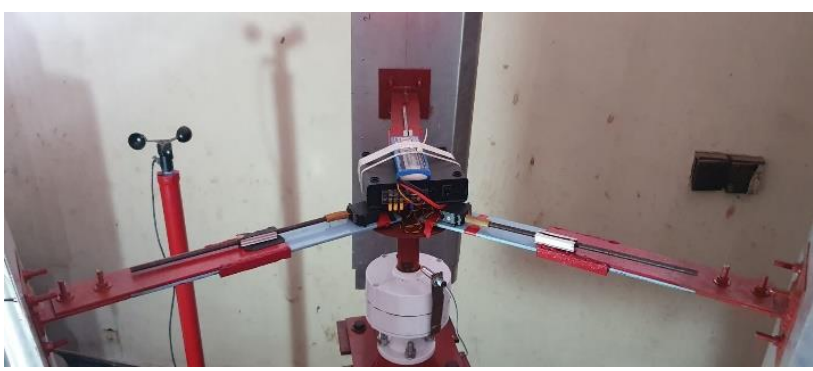

Figure. 15 Variable diameter rotor assembly

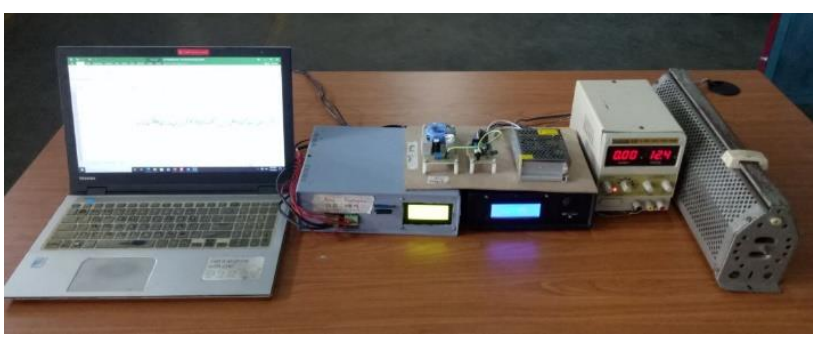

Figure. 16 Instruments support and data logger

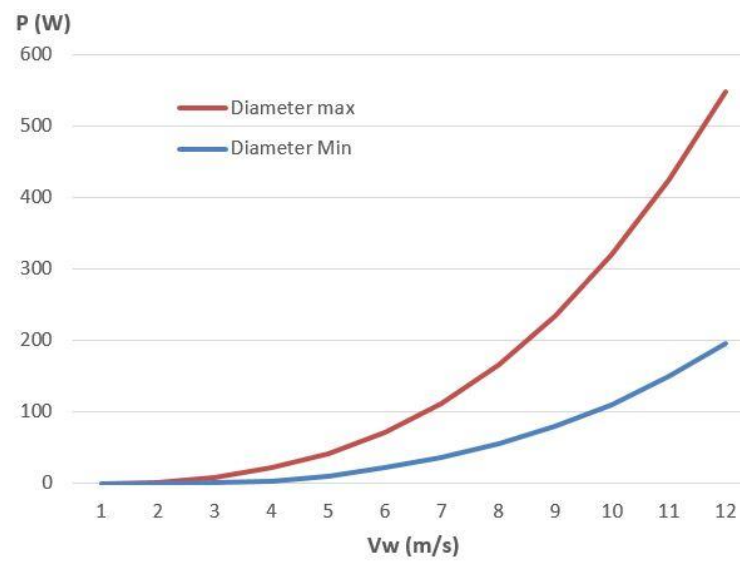

Figure. 17 The VDR power output 
Fig. 17 shows that the power output is exponential to wind speed. The wider the diameter, the higher the power output. When wind speed increases the rotor speed, the VAWT power output increases at fully extended of diameter; but when the diameter is retracted, the power output decreases at the same range of wind speed variation. It means that changes in diameter can provide cut-in speed at low wind speeds from starting operation and provide constant power output at different variable wind speeds through modification of diameter to match with the wind speed.

\section{Result and discussion}

The VDR with ANN-Fuzzy PID was tested using simulation and experiment in the laboratory scale. The VDR system consists of a fan, VDR Rotor, PMSG, converter, and resistive load. A fan is used as a simulated wind speed input with various controlled speed ranges from 1 to $12 \mathrm{~m} / \mathrm{s}$. The VDR rotor is a straight blade type (aluminium) with a blade height of $100 \mathrm{~cm}$, a diameter ranging from $75 \mathrm{~cm}$ to $150 \mathrm{~cm}$, for which the diameter is adjusted using a servo motor as an actuator as shown in Fig. 14. The actuator control interface uses a microcontroller which has 54 input output pins, the crystal oscillator used is $16 \mathrm{Mhz}$. The VDR rotor hub is connected to PMSG 500 Watt. PMSG output is connected to the three phase diode bridge rectifier, thereby converting the AC voltage of PMSG output into DC voltage. The rectifier output current is measured using the ACS754 current sensor, while the rectifier output voltage is measured by the voltage divider circuit. Both of analog signals are sent to the analog-to-digital conversion in microcontroller. These measured current and voltage are then used for PID controller to determine PWM's duty cycle. This PWM signals are employed for switching the IGBTs boost converter through an opto-transistor circuit. The signal power output and wind speed data are processed by Fuzzy interface in microcontroller to drive the VDR actuator. Data logger is used to record the wind speed, current, voltage, and power measurement data to be presented in graphical form. The relationship between wind speed and PMSG power is obtained by the measurement of the PMSG VAWT perfomed in a laboratory.

The simulation in Fig. 18 shows the effectiveness of the proposed method with regards:

- The capability to maintain constant power during wind speed changes.

- $\quad$ Presenting better cut-in speed.

In which the proposed system has been compared with another papers [16, 29], in which the first paper uses Fuzzy-PID for variable swept area (VSA) control [16], while the second paper uses the MLP ANN method for variable pitch control (VPC) [29]. On the other hand, the proposed system uses VDR with ANN-Fuzzy-PID. For fair comparison, the swept area of VDR, VSA, and VPC are using the same value and type (with small scale VAWT); moreover, three of which were tested at the same wind speed from $1 \mathrm{~m} / \mathrm{s}$ to $12 \mathrm{~m} / \mathrm{s}$. Therefore, the three methods can be observed at any difference or changes in wind speed.

Fig. 18 shows the simulation measurement with wind speeds ranging from $1 \mathrm{~m} / \mathrm{s}$ to $12 \mathrm{~m} / \mathrm{s}$. The result shows that VDR is able to start operation with faster cut-in wind speed of $2.2 \mathrm{~m} / \mathrm{s}$ and maintain constant power at low wind speeds, compared to fuzzy-PID controller. When the wind speed decreases from 12 $\mathrm{m} / \mathrm{s}$ to $10 \mathrm{~m} / \mathrm{s}$, VDR with ANN-Fuzzy-PID responds to the wind speed and obtains the correct VDR position varying the wind speed, and produces constant power while the wind speed changes. Moreover, VSA with Fuzzy-PID generates power output proportional to the wind speed; it can be seen at $0.7 \mathrm{~s}$ when the wind speed decreases from $12 \mathrm{~m} / \mathrm{s}$ to $10 \mathrm{~m} / \mathrm{s}$, the fuzzy PID power output drops from 200 Watt to 120 Watt, while at the same time the ANNFuzzy-PID holds constant power output at 200 Watt because the ANN predict the wind speed and becomes the input of Fuzzy controller to obtain the correct VDR position, thus accelerating the operation with faster cut-in wind speed at $2.2 \mathrm{~m} / \mathrm{s}$, compared to Fuzzy-PID, it can be seen at $0.1 \mathrm{~s}$ in which the operation of Fuzzy PID starts later and is delayed $0.05 \mathrm{~s}$ at $0.15 \mathrm{~s}$ with cut-in wind speed of $4.8 \mathrm{~m} / \mathrm{s}$.

VPC generates power output proportional to the wind speed. When the wind speed starts from $1 \mathrm{~m} / \mathrm{s}$ to $12 \mathrm{~m} / \mathrm{s}$, the VPC cut in speed is $5.9 \mathrm{~m} / \mathrm{s}$, slower than VDR and VSA. When the wind speed decreases from $12 \mathrm{~m} / \mathrm{s}$ to $10 \mathrm{~m} / \mathrm{s}$ at 0.7 second, the VPC power output drops from 200 Watt to 108 Watt.

The constant power starts to re-increase when the wind speed is at $12 \mathrm{~m} / \mathrm{s}$ at 0.8 second. It occurs because the pitch angle of the VPC is at the optimum angle position at low wind speed. Therefore, the power output is proportional to the wind speed, the change in pitch angle only occurs when the wind speed exceeds the rated value for the limiting power output. The experimental measurement can be seen in Fig. 19. The performance of VDR with ANNFuzzy-PID generates constant power despite changing wind speeds. It has been tested with random wind speed between $1 \mathrm{~m} / \mathrm{s}$ to $8 \mathrm{~m} / \mathrm{s}$, in which the VDR starts the operation with cut-in wind speed at $2 \mathrm{~m} / \mathrm{s}$. The wind speed limit is determined based on ANN forecasting, in which the wind speed prediction becomes fuzzy input, and the fuzzy output is the 

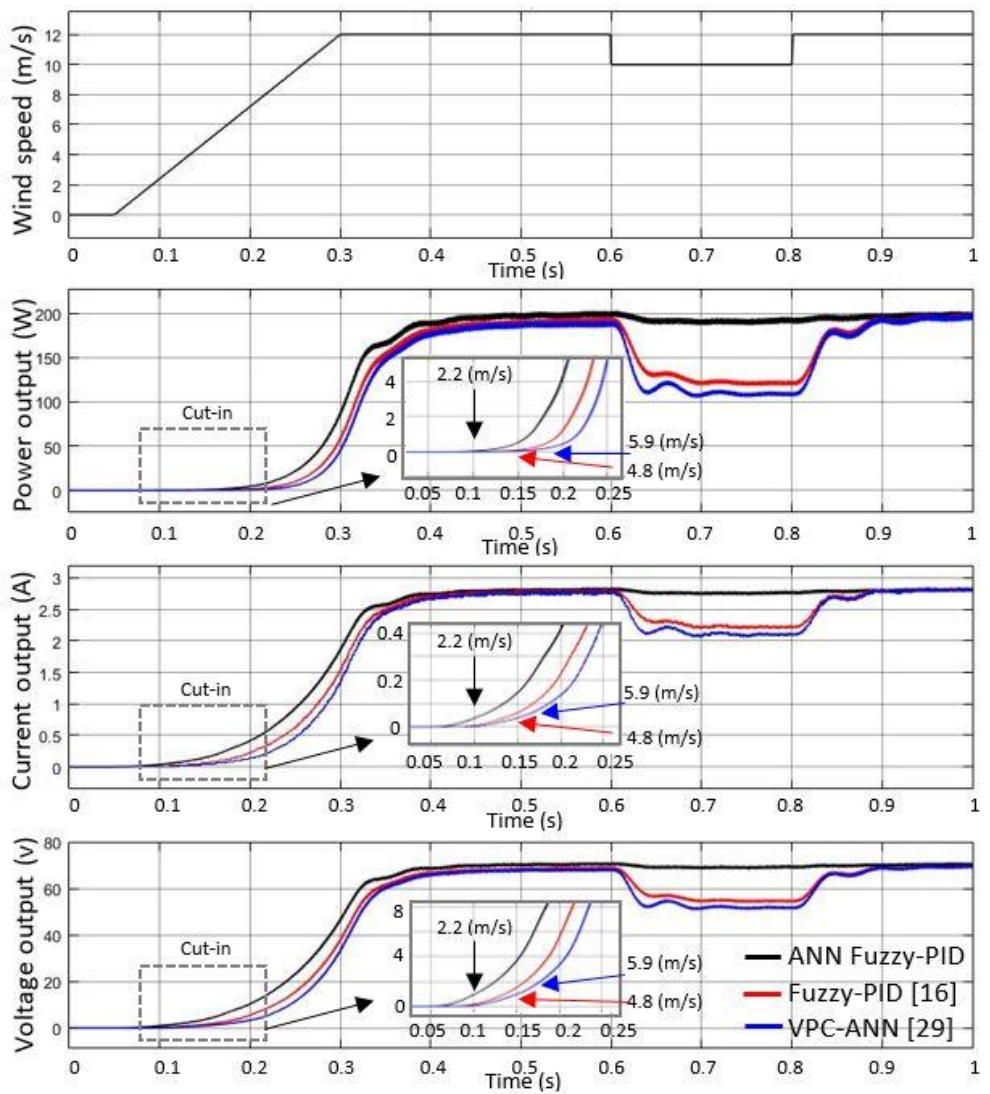

Figure. 18 Comparison performance of the proposed method VDR vs VSA [16] vs VPC [29]

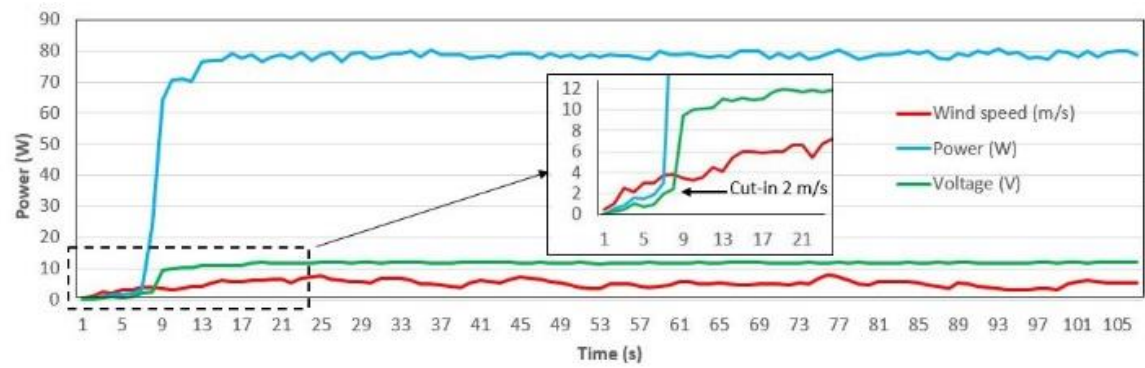

(a)

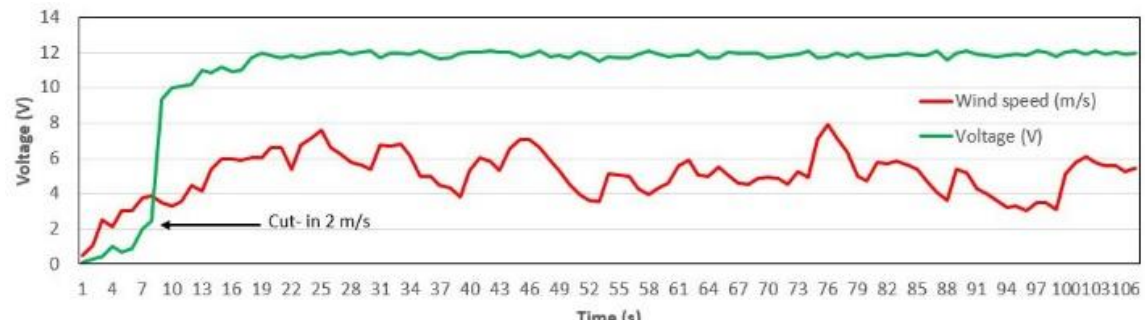

(b)

Figure. 19 Performance of VDR with ANN-Fuzzy-PID: (a) power vs volage vs wind speed and (b) voltage vs wind speed

diameter reference. The wind speed zone from cut-in speed to cut-out speed is divided into five cluster of wind speed as fuzzy membership function. The result shows that the VDR with ANN-Fuzzy-PID controller is far more powerful and generates better performance.

\section{Conclusion}

The VAWT performance with VDR method has been tested using simulation and experiment. It has been established that VDR with ANN-Fuzzy-PID is able to maintain constant power in spite of changing wind speeds, and optimization of VAWT starts at low 
cut-in wind speed of $2.2 \mathrm{~m} / \mathrm{s}$. The VDR with ANNFuzzy-PID controller has better performance and manages the VDR actuator to overcome the wind speed and maintain constant power with an increased power by $37 \%$. The result of VDR system with ANNFuzzy PID controller indicates that it is able to operate VAWT with faster cut-in wind speed and wider extract power at low wind speeds. Future research projects focusing on this topic should apply VDR with other artificial intelligent controller to increase the VAWT performance more efficiently.

\section{Conflicts of Interest}

The authors declare no conflict of interests.

\section{Author Contributions}

Planning and converter simulation, M.A.; VAWT experimenting, J.F.; wind speed forecasting verification, J.F.; model development, J.F.; data analysis, S.; writing the manuscript, M.A. and J.F.; theoretical framework development, J.F. and S.; supervision, M.A.

\section{Acknowledgments}

The researchers would like to express their gratitude to Institut Teknologi Sepuluh Nopember and Politeknik Negeri Banjarmasin for the research opportunity, and the LPDP of the Indonesian Ministry of Finance for the scholarship. The researchers also thank their parents.

\section{Notations}

$\begin{array}{ll}A & \text { swept area } \\ B & \text { viscous friction of the rotor } \\ C p & \text { power coefficient } \\ D & \text { diameter } \\ D_{c l} & \text { duty cycle } \\ h & \text { height } \\ J & \text { inertia } \\ K_{p} & \text { proportional gain } \\ K_{i} & \text { integral gain } \\ K_{d} & \text { derivative gain } \\ L & \text { inductor } \\ P & \text { power } \\ P_{m} & \text { mechanical power } \\ P_{\text {in }} & \text { power input } \\ P_{\text {out }} & \text { power output } \\ P_{\text {ref }} & \text { reference power } \\ R_{\text {in }} & \text { resistance } \\ R_{L} & \text { resistive load } \\ r_{t} & \text { radius } \\ T_{e} & \text { electromagnetic torque }\end{array}$

$\begin{array}{ll}T_{m} & \text { mechanical torque } \\ T_{\text {on }} & \text { time on } \\ T_{\text {off }} & \text { time off } \\ T_{s} & \text { switching priod } \\ t & \text { time } \\ V_{i} & \text { voltage input } \\ V_{o} & \text { voltage output } \\ V_{d c} & \text { DC voltage } \\ V_{w} & \text { wind speed } \\ \rho & \text { air density } \\ \theta & \text { pitch angle } \\ \lambda & \text { tip speed ratio } \\ \omega_{m} & \text { rotational speed } \\ \Delta D & \text { delta diameter } \\ e P & \text { error power } \\ \delta e P & \text { delta error power }\end{array}$

\section{References}

[1] S. Marhraoui, A. Abbou, Z. Cabrane, S. E. Rhaili, and N. El Hichami, "Fuzzy logic-integral backstepping control for PV grid-connected system with energy storage management", International Journal of Intelligent Engineering and Systems, Vol. 13, No. 3, pp. 359-372, 2020.

[2] A. Barnes and B. Hughes, "Determining the impact of VAWT farm configurations on power output", Renewable Energy, Vol. 143, pp. 11111120, 2019.

[3] A. V. Hemeyine, A. Abbou, N. Tidjani, M. Mokhlis, and A. Bakouri, "Robust takagi sugeno fuzzy models control for a variable speed wind turbine based a DFI-generator", International Journal of Intelligent Engineering and Systems, Vol. 13, No. 3, pp. 90-100, 2020.

[4] S. Rhaili, A. Abbou, S. Marhraoui, R. Moutchou, and N. Hichami, "Robust Sliding Mode Control with Five Sliding Surfaces of Five-Phase PMSG Based Variable Speed Wind Energy Conversion System”, International Journal of Intelligent Engineering and Systems, Vol. 13, No. 4, pp. 346-357, 2020.

[5] S. Abbaszadeh, S. Hoerner, T. Maître, and R. Leidhold, "Experimental investigation of an optimised pitch control for a vertical-axis turbine", IET Reneable Power Generation, Vol. 13, No. 16, pp. 3106-3112, 2019.

[6] A. Das, K. B. Chimonyo, and R. Kumar, "Vertical Axis and Horizontal Axis Wind School of Electrical Engineering", In: Proc. of International Conf. on Energy, Communication, Data Analytics and Soft Computing, pp. 2660 2669, 2017.

[7] J. Fadil, Soedibyo, and M. Ashari, "Performance comparison of vertical axis and horizontal axis 
wind turbines to get optimum power output", In: Proc.of International Conf. on Quality in Research. International Symposium on Electrical and Computer Engineering, pp. 429433, 2017.

[8] Y. Ahmudiarto Y, A. Romadoni, B. Karyanto , T. Admono , B. Nugroho , R. Chin, and A. Budiyono, "Performance Analysis of Novel Blade Design of Vertical Axis Wind Turbine", In: Proc. of International Conf. on Sustainable Energy Engineering and Application: Innovative Technology Toward Energy Resilience, pp. 175-181, 2019.

[9] M. O. Korukcu, "Numerical Investigation of Vertical Axis Wind Turbine for Different Parameters", In: Proc. of nternational Conf. on Smart and Sustainable Technologies., pp. 5-9, 2019.

[10] S. M. Agravat, N. V. S. Manyam, S. Mankar, and T. Harinarayana, "Theoretical Study of Wind Turbine Model with a New Concept on Swept Area",Energy and Power Engineering. Vol. 7, No.4. pp. 127-134, 2015.

[11] L. Chen, Y. Yang, Y. Gao, Z. Gao, Y. Guo, and L. Sun, "A novel real-time feedback pitch angle control system for vertical-axis wind turbines", Journal of Wind Engineering and Industrial Aerodynamics, Vol. 195, pp. 1-13,2019.

[12] M. Fdaili, A. Essadki, M. Nadour, and T. Nasser, "Comparative Study of MPPT and Pitch Angle Control Strategies for a Wind Energy Conversion System", In: Proc. of International Renewable and Sustainable Energy Conf., pp. $1-6,2018$.

[13] P. Lap-arparat and T. Leephakpreeda, "Realtime maximized power generation of vertical axis wind turbines based on characteristic curves of power coef fi cients via fuzzy pulse width modulation load regulation", Energy, Vol. 182, pp. 975-987, 2019.

[14] A. Goude and F. Bülow, "Robust VAWT control system evaluation by coupled aerodynamic and electrical simulations q", Renewable Energy, Vol. 59, pp. 193-201, 2013.

[15] K. G. Upadhaya, A. Verma, M. M. Tripathi, and R. Kumar, "Design of adjustable blade wind turbine for constant generated power", In: Proc. of IEEE Power India International Conf. 2014, pp. 0-5, 2014.

[16] J. Fadil, S. Soedibyo, and M. Ashari, "Novel of vertical axis wind turbine with variable swept area using fuzzy logic controller", International Journal of Intelligent Engineering and Systems, Vol. 13, No. 3, pp. 256-267, 2020.
[17] M. Imraan, R. N. Sharma, and R. G. J. Flay, "Wind tunnel testing of a wind turbine with telescopic blades: Theinfluence of blade extension", Energy, Vol. 53, pp. 22-32, 2013.

[18] S. Sivamani, M. P. T, M. Sohail, M. T, and H. V, "Experimental data on load test and performance parameters of a LENZ type vertical axis wind turbine in open environment condition", Data in Brief, Vol. 15, pp. 1035-1042, 2017.

[19] T. K. Barlas and G. A. M. van Kuik, "Review of state of the art in smart rotor control research for wind turbines", Progress in Aerospace Sciences, Vol. 46, No. 1, pp. 1-27, 2010.

[20] E. Antar, A. El Cheikh, and M. Elkhoury, "A dynamic rotor vertical-axiswind turbine with a blade transitioning capability", Energies, Vol. 12, No. 8, 2019.

[21] T. L. Van and T. Hai, "Advanced Pitch Angle Control Based on Fuzzy Logic for VariableSpeed Wind Turbine Systems", IEEE Transactions on Energy Conversion., Vol. 7, No. 3, pp. 259-266, 2013.

[22] Y. Guo, X. Li, L. Sun, Y. Gao, Z. Gao, and L. Chen, "Aerodynamic analysis of a step adjustment method for blade pitch of a VAWT", Journal of Wind Engineering and Industrial Aerodynamics, Vol. 188, No. October 2018, pp. 90-101, 2019.

[23] S. Watson, A. Moro, V. Reis, C. Baniotopoulos, S. Barth, G. Bartoli, F. Bauer, E. Boelman, D. Bosse, A. Cherubini, A. Croce, L. Fagiano, M. Fontana, A. Gambier, K. Gkoumas, C. Golightly, M. Latour, P. Jamieson, J. Kaldellis, A. Macdonald, J.Murphy, M. Muskulus, F. Petrini, L. Pigolotti, F. Rasmussen, P. Schild, R. Schmehl, N. Stavridou, J. Tande, N. Taylor, T. Telsnig, and R. Wiser, "Future emerging technologies in the wind power sector: A European perspective", Renewable and Sustainable Energy Reviews, Vol. 113, pp. 1-21, 2019.

[24] M. H. Mughal and L. Guojie, "Review of pitch control for variable speed wind turbine", In: Proc. of IEEE 12th International Conf. on Ubiquitous Intelligence and Computing, pp. 738-744, 2016.

[25] J. Fadil, Soedibyo, and M. Ashari, "Performance Analysis of Vertical Axis Wind Turbine with Variable Swept Area", In: Proc. of International Seminar on Intelligent Technology and Its Application, pp. 217-221, 2017.

[26] J. Zwierzchowski, P. Andrzej Laski, S. Blasiak, J. E. Takosoglu, D. S. Pietrala, G. F. Bracha, and L. Nowakowski, "Model tests of wind turbine 
with a vertical axis of rotation type Lenz 2", In: Proc. of EPJ Web of Conf., pp. 1-7, 2017.

[27] L. Wang, L. Cao, and L. Zhao, "Non-linear tip speed ratio cascade control for variable speed high power wind turbines: A backstepping approach", IET Renewable Power Generation, Vol. 12, No. 8, pp. 968-972, 2018.

[28] B. Zouzou, I. Dobrev, F. Massouh, and R. Dizene, "Experimental and numerical analysis of a novel Darrieus rotor with variable pitch mechanism at low TSR", Energy, Vol. 186, p. 115832, 2019.

[29] G. Abdalrahman, W. Melek, and F. S. Lien, "Pitch angle control for a small-scale Darrieus vertical axis wind turbine with straight blades (H-Type VAWT)", Renewable Energy, Vol. 114, pp. 1353-1362, 2017.

[30] P. Lap-Arparat and T. Leephakpreeda, "Realtime maximized power generation of vertical axis wind turbines based on characteristic curves of power coefficients via fuzzy pulse width modulation load regulation", Energy, Vol. 182, pp. 975-987, 2019.

[31] A. Hossain, R. Singh, I. A. Choudhury, and A. Bakar, "Energy efficient wind turbine system based on fuzzy control approach", Procedia Engineering, Vol. 56, pp. 637-642, 2013.

[32] A. S. Wardhana, "Optimal Control of Robotic Arm System to Improve Flux Distribution on Dual Parabola Dish Concentrator", International Journal of Intelligent Engineering and Systems, Vol. 13, No. 1, 2020.

[33] R. I. Putri, M. Pujiantara, A. Priyadi, T. Ise, and M. H. Purnomo, "Maximum power extraction improvement using sensorless controller based on adaptive perturb and observe algorithm for PMSG wind turbine application", IET Electric Power Applications, Vol. 12, No. 4, pp. 455-462, 2018.

[34] A. K. Chauhan, M. Raghuram, and S. K. Singh, "Extended boost three phase matrix converter using switched capacitor topology having buck boost ability", In: Proc. of IEEE International Conf. on Power Electronics, Drives and Energy Systems, pp. 1-4, 2017.

[35] M. Rahimi, "Modeling, control and stability analysis of grid connected PMSG based wind turbine assisted with diode rectifier and boost converter", International Journal of Electrical Power and Energy Systems, Vol. 93, pp. 84-96, 2017.

[36] N. Rana, M. Kumar, A. Ghosh, and S. Banerjee, "A Novel Interleaved Tri-State Boost Converter with Lower Ripple and Improved Dynamic Response", IEEE Transactions on Industrial
Electronics, Vol. 65, No. 7, pp. 5456-5465, 2018.

[37] H. Liu, Y. Ji, L. Wang, and P. Wheeler, "A family of improved magnetically coupled impedance network boost DC-DC converters", IEEE Transactions on Power Electronics, Vol. 33, No. 5, pp. 3697-3702, 2018.

[38] Y. F. Ren, "Control Strategy of Maximum Wind Energy Capture of Direct-Drive Wind Turbine Generator Based on", In: Proc. of Asia-Pacific Power and Energy Engineering Conf., pp. 5-8, 2010. 